\title{
Study on Rural Tourism Industry Competitiveness of Shaanxi Province Yong Peng ${ }^{1, a}$ \\ ${ }^{1}$ Xi'an International University, Xi'an, Shaanxi, 710077 \\ ${ }^{a}$ email
}

\author{
Keywords: Competitiveness; Shaanxi Province; Rural Tourism Industry
}

\begin{abstract}
Rural tourism industry in recent years, China's tourism industry has become an important part of it is agricultural activity and tourism consumption activities together organically, become a new way to travel. As China's Shaanxi Province, the birthplace of culture, "Qin", "Tang" cultural gathering place, has enough tourism resources. This article will present situation and the lack of Shaanxi Province rural tourism industry to a detailed analysis of competitiveness.
\end{abstract}

\section{Introduction}

Rural tourism is a collection of idyllic rural natural, agricultural activities or folk cultural activities, residential and cultural tourism attractions to attract tourists in the form of one kind of tourism. With the further development of China's tourism industry, rural tourism industry has become one of the premier tourist destination of choice people. Shaanxi Province is the birthplace of our country and gathering place for cultural and Qin Tang culture, in the vicinity of the village also retains a heavy cultural heritage in traditional customs. At the same time as the birthplace of the Silk Road, Shaanxi Province, but also possess other people's customs. Whether it is from the culture, history, customs, Shaanxi Province, rural tourism are sufficient competitiveness.

\section{Development Status of Rural Tourism Industry in Shaanxi Province}

In the past, the tourism industry in Shaanxi Province, the city tourism industry and cultural tourism industry occupies a large part. Qin Terracotta Warriors and Horses of Qin Shi Huang as witness the emperor and Yang Yuhuan love Huaqing Pool, known as "the best in the world risks" as well as the Bell and Drum Tower Xi'an Huashan room, large Pagodas are conventional in Shaanxi Province key tourist attractions. But as people yearn for the idyllic, tourist part of Shaanxi Province also increased related to the tourism industry, so that visitors to the city no longer limited to Shaanxi, but better able to enjoy the sandy transition zone Shaanxi Loess Plateau region Guanzhong Plain region, the Qinling mountains, the Han River basin area and Daba mountains region and other natural scenery. Today, annual revenue in Shaanxi Province rural tourism industry has accounted for one-third of total revenue, and kept the upward trend [1].

In the development of rural tourism products in the process, part of Shaanxi Province tourism maximum guarantee the product system of "flavor" of, as far as possible in front of the most primitive state rendered tourists. Integration of the various rural tourism resources, to develop a set of integrated experiences of rural life, rural tourism, leisure and cultural interaction of tourism products. Allowing visitors to experience country life up close at the same time, we understand the culture and natural style from Shaanxi earth.

With the Shaanxi Provincial Tourism Department of Shaanxi Province to vigorously promote rural tourism industry and investment, and tourism resources for the characteristics of each region to develop tourism activities with local characteristics, such as the well-being of the Dragon Boat Festival, Lintong pomegranate Festival, Apple Festival Weinan, northern Shaanxi Folk Song Festival and so on. The use of modern media communication technologies, the promotion of good Shaanxi Province rural tourism products out. Greatly enhance the visibility of Shaanxi Province rural tourism products, thus promoting the people's Shaanxi Province rural tourism interest and attention.

Since Shaanxi Province began to develop rural tourism industry, the relevant parts has 
introduced five institutional guidelines on rural tourism, including the "Shaanxi Province rural tourism development guidance", "Shaanxi Provincial Tourism Bureau, Shaanxi Provincial Agriculture Department to vigorously to promote rural tourism development of the notice "and" Shaanxi Province industrial and agricultural tourism demonstration sites Cultivation and management guidance "[2]. Meanwhile, Shaanxi Province Ayutthaya also set up a special leading group for rural tourism, provide specific guidance and direction for the development of tourism industry in rural Shaanxi Province, local rural tourism industry provides the necessary political support.

\section{The Lack of Rural Tourism Industry in Shaanxi Province}

At present, Shaanxi Province, rural tourism is mainly developed by the local farmers and rural enterprises, it has obvious personal subjectivity in the construction process, it does not meet the essential requirements of the tourism market. Meanwhile, rural tourism resources can not do rational development and utilization. At present, Shaanxi Province, rural tourism is still stuck in the use of existing orchards, pasture and other resources, no digging rural tourism potential depth. But did not establish the necessary linkages between each village, lack of unified planning and rational layout, limiting the choice of tourists tourism products.

Development Model 2.2 insufficient diversification of the tourism industry

Shaanxi Province rural industry is still in the extensive mode of operation, most villages do not make good use of the characteristics of local tourism resources, it is the development of more locally available natural resources. As a result, it is most likely to cause similar tourism products, tourism products is not enough local characteristics and cultural connotation, it is easy for visitors to "fatigued." Such as Shaanxi Lintong can be made two tours, one is Chinese culture-based tourism products, so that visitors can appreciate the modern Chinese nation is a history from ancient times of the past, a taste from Jiangzhai site to the ancient matriarchal society style, to realize the first Chinese emperor Qin Terracotta Warriors and Horses of tolerance; from the emperor and Yang Yuhuan love not speak sorrowful, Zhang Xueliang and Yang Hucheng to persuade Chiang Kai-shek's soldiers remonstrance national interests. Is a local natural landscape, Lintong is typical of the Guanzhong Plain terrain, it is an important breadbasket. Tourism can be part of the development part of the field, allowing visitors to experience the process of growing food, and show visitors modern agricultural techniques. Allowing visitors to really understand modern agricultural technology advanced and grain cultivation is not easy. And in accordance with the change of seasons, you can change the contents of activities, such as the fall can be established with pomegranate theme of tourism activities.

The tourism industry is a service industry, the relevant staff must have enough sense of service and professional quality, to provide quality travel services for tourists, it is also important to show the local tourism image window. However, due to rural tourism resources in Shaanxi Province was developed by the local township government and farmers, so the management philosophy and way of tourism service personnel are relatively backward, too much emphasis on short-term interests to achieve, while ignoring the long-term development interests. Travel service personnel without professional training on the job, can not provide high-quality travel services for tourists.

Tourism is the most important building transportation, meals and lodging, most of the tourists are holding casual attitude to tourism, so naturally higher for tourism infrastructure requirements. But in some villages in Shaanxi Province, the traffic is very convenient place to stay and eat are very simple, simply can not provide the basic conditions for tourist visitors. Resulting in some villages even have a very rich tourism resources, can not be effectively developed and utilized.

\section{Specific Analysis of Shaanxi Rural Tourism Industry Competitiveness}

Simple, tourism is the "food, housing, transportation, travel, shopping and entertainment" component. Part of the rural tourism industry not only tourism, but also with transportation, accommodation and catering industry are closely linked. Therefore, to analyze the competitiveness 
of Shaanxi rural tourism industry, it should be from the following aspects.

Shaanxi Province, since ancient times is a major tourist province, which is the capital city of Xi'an, the ancient capital city, is the capital of the Tang Dynasty; and the other Xianyang city, known as China's first empire, the Huashan Huayin County is more dangerous known world, in addition or unique landforms on the Loess Plateau, has a rough folk Xintianyou. In terms of culture, history, natural scenery and folk style, etc., all rural Shaanxi Province has a rich tourism resources. As a veteran of the tourist province, is a certain visibility of tourism and tourist reception capacity. Despite previous tour in Xi'an in Shaanxi Province's main tourism product focus and center, but also for the surrounding rural tourism industry has laid a good foundation for the development. A survey shows that rural tourism in Shaanxi cultural characteristics and scenic sightseeing tourists have a high visibility in [3]. Tourism and related sectors should be rational use of these "old" spots, appropriate publicity of rural tourism.

Data shows that in 2015 in Shaanxi Province rural tourism trips will reach 66.438 million, total tourism revenue will reach 13.8 billion yuan. Some experts estimate that by 2020, Shaanxi Province rural tourism trips will reach 96.745 million, total revenue of 29.31 billion yuan [4]. It can be said with the Shaanxi Provincial Rural tourism is a very good market prospects. Currently Shaanxi Province rural tourism source market mainly young tourists mainly, most visitors from Shaanxi province, and fewer tourists in other parts of the surrounding area. It can understand the future rural tourism of Shaanxi still has much room for development. In Shaanxi Province, rural tourism, visitors monthly income of 10,000 yuan accounted for 40\%, which in Shaanxi Province rural tourism industry to high-end development has provided good support. Shaanxi Province, mainly in the rural tourism in the short tourist-oriented, the number of day trips accounted for $56 \%$, the number of outer stay less than three days $42 \%$ [5].

Public transport is the main mode of rural tourism in Shaanxi Province. 50\% of visitors will choose bus, about $30 \%$ of visitors will choose the train, to fail $20 \%$ of the tourists choose traveling by car [6]. Upon arrival in, only $26 \%$ of visitors willing to explore on foot, $6 \%$ of visitors are willing to take the cable car tour. With respect to travel more mature provinces such as Zhejiang, Sichuan and other regions, driving in Shaanxi Province and the like should be improved. With the improvement of transportation scenic rural tourism infrastructure construction gradually improve, there will be more willing to tourists traveling by way of rural tourism.

Shaanxi Province rural tourists, mostly from nearby cities, such high interest of tourists to rural features food, green food, farm vegetables, such diets are willing to occupy most of the tourism in the diet. In rural tourism, the per capita consumption of tourists, catering costs 50 yuan / number of people accounted for $18 \%$ of food and beverage cost 50 to 60 yuan / person at the number of 34\%. In the shopping and entertainment, spend less than 100 yuan / the number of people accounted for 49\%. As can be seen, Shaanxi Province rural tourism industry should vigorously develop the characteristics of the local farmers have mid-range food consumption, enhance the spending power of high-end tourists.

\section{Conclusion}

Overall, Shaanxi Province rural tourism industry is still very competitive. Tourist part of Shaanxi Province to fully explore the local countryside tourism resources, the use of existing tourist image, reputation and reception based on the establishment of urban-based, full development and utilization of rural natural scenery, cultural and historical tourism resources. Increase rural tourism industry infrastructure, for each rural tourism have to do proper planning, connecting villages, the establishment of a system of rural tourism industry circle, give full play to its own characteristics of each village. Increase rural tourism transportation construction, tourism products based mostly short and medium term, an increase in the proportion of rural tourism traveling by car. At the same time increase the development of mid-range farm characteristics diet to enhance the high-end tourists spending power, efforts to expand the entire rural tourism market in Shaanxi Province. 


\section{Acknowledgements}

Shaanxi Province, the major theoretical social science research and practical problems 2016 year project, project number: $2016 \mathrm{C} 075$.

\section{References}

[1] Hu Fenlin, Ding Hua, Guo Wei. Shaanxi Province Rural Tourism Resources Evaluation and special advantage of [J]. Anhui Agricultural Sciences, 2011,17: 10537-10538 + 10586.

[2] Ding Hua, Yue Dan, Dong Feng. Rural tourism development in Shaanxi Province Dong wind thinking [J]. Anhui Agricultural Sciences, 2011,24: 14871-14873 + 14920.

[3] Dong Xiaoying. Shaanxi Province Rural Tourism Development Model and Strategy [J]. travel overview (industry version), 2011, 09: 63-64.

[4] Liu Xiaoming. Shaanxi Province rural tourism development of low-carbon SWOT analysis [J]. Xi'an Shiyou University (Social Science Edition), 2013,03: 12-16.

[5] Han Shen, Li Hua. Shaanxi Province Fengxian County Rural Tourism SWOT analysis [J]. Beijing Agriculture, 2014, 03: 269-270.

[6] Fang Lin. Liu Longlong. Situation rural tourism development in Shaanxi Province [J]. Rural Economy and Science, 2016, 06: 65 + 68. 